\title{
Spontaneous intracranial hypotension complicated with cerebral venous thrombosis and subdural effusion: a case report
}

\author{
Murali Krishna Menon ${ }^{1}$, Thara Prathap ${ }^{2}$, Muhammed Jasim Abdul Jalal ${ }^{3}$ \\ ${ }^{1}$ Department of Neurology, Lakeshore Hospital and Research Centre, Ernakulam 682040, Kerala, India. \\ ${ }^{2}$ Department of Radiology, Lakeshore Hospital and Research Centre, Ernakulam 682040, Kerala, India. \\ ${ }^{3}$ Department of Family Medicine, Lakeshore Hospital and Research Centre, Ernakulam 682040, Kerala, India.
}

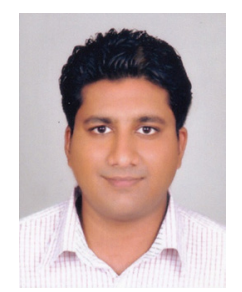

Dr. Muhammed Jasim Abdul Jalal, a family physician, trained in general medicine, general surgery, women and child health and preventive medicine. He believes in the concept of medical care with a preventive and holistic approach. He has special interest in clinical neurology.

\section{A B S T R A C T}

Spontaneous intracranial hypotension treatment can be complicated by concomitant cerebral venous thrombosis and subdural hematoma. A 48 years old male, presenting orthostatic headache and neck pain for 1 month displayed sagittal sinus thrombosis and bilateral subdural effusions, as well as extradural fluid collection at T3-T8 level, upon magnetic resonance imaging. Cerebrospinal fluid opening pressure was $50 \mathrm{mmH}_{2} \mathrm{O}$, and a leak was confirmed at $\mathrm{C} 2-\mathrm{C} 3$ level by computed tomography (CT) myelogram. The presence of subdural hematoma precluded anticoagulation treatments. An autologous epidural blood patch at C2-C3 level under CT guidance improved the patient's condition, remaining free of residual symptoms or recurrence at six-month follow-up.

Key words: Spontaneous intracranial hypotension; cerebral venous thrombosis; subdural effusion; autologous epidural blood patch

\section{INTRODUCTION}

Orthostatic headache, low cerebrospinal fluid (CSF) pressure, and noninterrupted diffuse pachymeningeal enhancement observed upon magnetic resonance imaging (MRI) of the brain, characterize spontaneous intracranial hypotension (SIH). The estimated annual incidence of this uncommon disorder is 5 per 100,000, and its cause lies in spontaneous CSF leaks that result in CSF hypovolemia and hypotension (CSF opening pressure $<60 \mathrm{mmH}_{2} \mathrm{O}$ ). ${ }^{[1]} \mathrm{CSF}$ composition may be normal or show increased protein content and

Corresponding Author: Dr. Muhammed Jasim Abdul Jalal,

Department of Family Medicine, Lakeshore Hospital and

Research Centre, Nettoor.P.O., Maradu, NH 47-Byepass.

Ernakulam 682040, Kerala, India. E-mail: poolspuff@gmail.com

\begin{tabular}{|l|l|}
\hline \multicolumn{3}{|c|}{ Access this article online } \\
\hline Quick Response Code: & Website: \\
\hline $\mathbf{y}$ & http://nnjournal.net \\
\cline { 1 - 2 } & \\
\hline $\mathbf{D}$ & DOI: \\
\hline
\end{tabular}

pleocytosis.

SIH cases occasionally present with concomitant subdural effusions and, more rarely, cerebral venous thrombosis (CVT) (2\% of patients). ${ }^{[3]}$ The most characteristic brain MRI finding in SIH is diffuse pachymeningeal enhancement, that is caused by an increase in venous blood volume secondary to the loss of CSF pressure. ${ }^{[4]}$ This alteration can lead to subdural hematoma and CVT through two main mechanisms: (1) SIH is associated with rostrocaudal sagging of the brain due to the loss of CSF buoyancy, ${ }^{[4]}$ resulting in a negative intracranial pressure gradient that may damage the venous endothelial lining by stretching the cerebral vessels, and can produce tears in bridging

This is an open access article distributed under the terms of the Creative Commons Attribution-NonCommercial-ShareAlike 3.0 License, which allows others to remix, tweak, and build upon the work non-commercially, as long as the author is credited and the new creations are licensed under the identical terms.

For reprints contact: service@oaepublish.com

How to cite this article: Menon MK, Prathap T, Jalal MJA. Spontaneous intracranial hypotension complicated with cerebral venous thrombosis and subdural effusion: a case report. Neuroimmunol Neuroinflammation 2016;3:104-8

Received: 06-09-2015; Accepted: 05-12-2015 
veins in the dural border cell layer, causing them to rupture and leading to subdural hematoma; (2) the loss of CSF volume reduces absorption of CSF into the cerebral venous sinuses, resulting in increased blood viscosity in the venous compartment, ${ }^{[5]}$ which could contribute to dural sinus thrombosis in patients with risk factors for thrombosis. The general consensus is that CVT should be treated with heparin, since a meta-analysis concluded that this treatment is safe and is associated with a clinical trend (not statistically significant) of reduction in the risk of death and dependency. Thus, most of the reported SIH patients with CVT have been treated with anticoagulation so far along with bed rest, hydration and epidural blood patches (EBP) [Table 2]. ${ }^{[6-14]}$ On the other hand, cases of large subdural hemorrhage require surgical drainage and treatment of the underlying cause of SIH. Most $\mathrm{SIH}$ patients without other complications recover after bed rest with foot end elevation, hydration and steroid therapy. Nevertheless, the mainstay of SIH treatment is the application of EBP at the CSF-leak site (injection of 10-20 mL of autologous blood into the spinal epidural space). ${ }^{[15]}$ Relief of symptoms, particularly orthostatic headache, is often dramatic after EBP, and if it fails it can be repeated. On the other hand, direct EBP at the cervical area is challenging due to the narrow space of region and its proximity to important neural structures, therefore, this treatment is not performed in all cervical-leak cases. With this case report we aimed to provide further evidence that
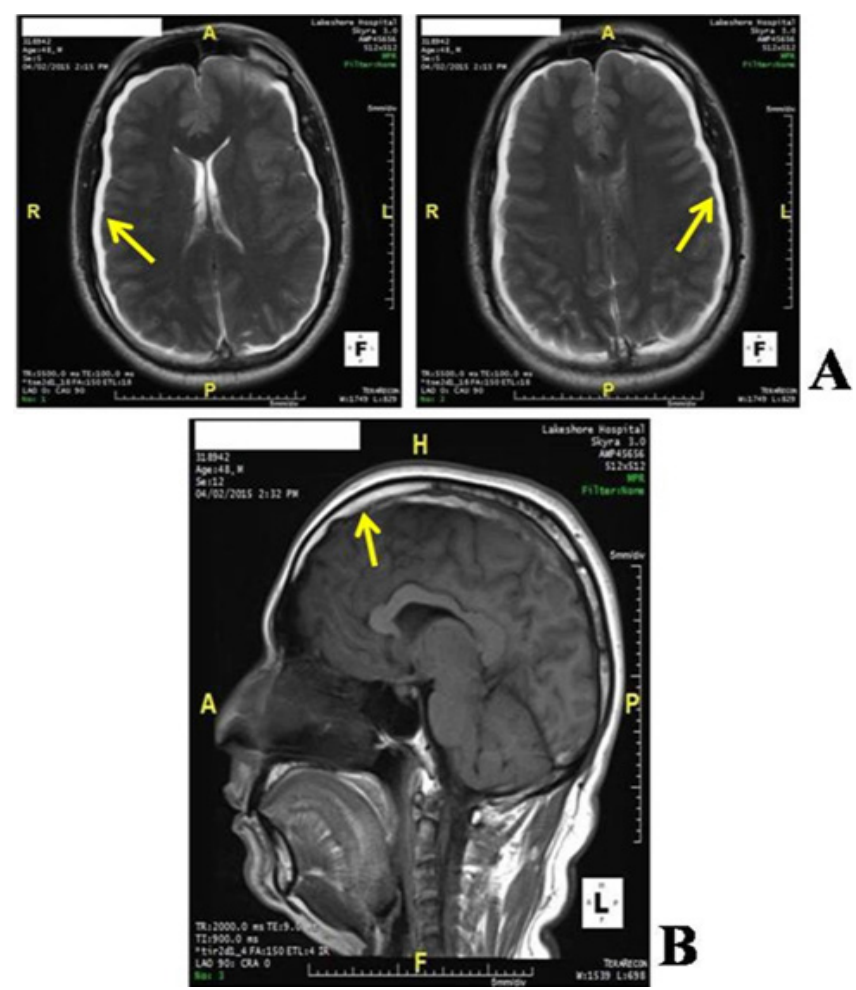

Figure 1: MRI brain. (A) T2 weighted sequences showing bilateral symmetrical fronto-parietal and occipital subdural effusions (as marked by the arrow); (B) T1 weighted sequences showing saggital sinus thrombosis (as marked by the arrow)
EBP is a feasible and efficient treatment for SIH with CSF leak in the cervical area, subdural hematoma and CVT.

\section{CASE REPORT}

A 48 years old Indian male presented with headache and neck pain of 1 month duration. The patient had severe occipital headache with visual analogue score of 9. The headache worsened in the upright position and was completely relieved after lying down. The patient was otherwise normal, without any significant past clinical history.

On examination, the patient was conscious, oriented and afebrile, with a pulse rate of 82 beats per minute and blood pressure of 130/80 mmHg. Eye movements were normal in all directions and there was no sign of nystagmus. Both pupils were equal and reactive to light. Cranial nerve and fundus examinations were also normal and no motor weakness or sensory loss was present. Flexor plantar response was positive and bilateral. No signs of meningeal irritation nor focal neurological deficits were found.

T2 weighted sequences from the MRI of the brain showed bilateral symmetrical fronto-parietal and occipital subdural effusions [Figure 1A], while $\mathrm{T} 1$ weighted sequences unveiled sagittal sinus thrombosis [Figure 1B]. T2 sequences from the spine MRI revealed elliptical high signal extra axial collection posterior to the spinal cord at T3 to T8 level, which was suggestive of CSF leak [Figure 2].

A lumbar puncture with CSF manometry was performed under aseptic conditions, finding a CSF opening pressure of $50 \mathrm{mmH}_{2} \mathrm{O}$. CSF content analysis [Table 1] showed elevated proteins [normal CSF protein ranges from $20-40 \mathrm{mg} / \mathrm{dL}$ ]. CT myelography revealed extradural contrast extravasation at C2-C3 level [Figure 3A].

Vasculitic work-up yielded negative results for antinuclear antibody, anti-double stranded DNA antibody, perinuclear anti-neutrophil cytoplasmic antibody, cytoplasmic anti-neutrophil cytoplasmic antibody and anti-phospholipid antibody. Thrombophilia screening resulted also negative, as anti-thrombin, protein $\mathrm{C}$ and protein $\mathrm{S}$ were normal. Factor V Leiden

\begin{tabular}{ll}
\hline Table 1: Cerebrospinal fluid analysis \\
\hline Parameters & Results \\
\hline CSF colour & Clear fluid, no xanthochromia, no turbidity \\
CSF pressure & $50 \mathrm{mmH}_{2} \mathrm{O}$ \\
CSF protein & $315 \mathrm{mg} / \mathrm{dL}$ \\
CSF sugar & $93 \mathrm{mg} / \mathrm{dL}$ \\
CSF cell count & Occassional RBCs only
\end{tabular}

CSF: cerebrospinal fluid; RBCs: red blood cells 


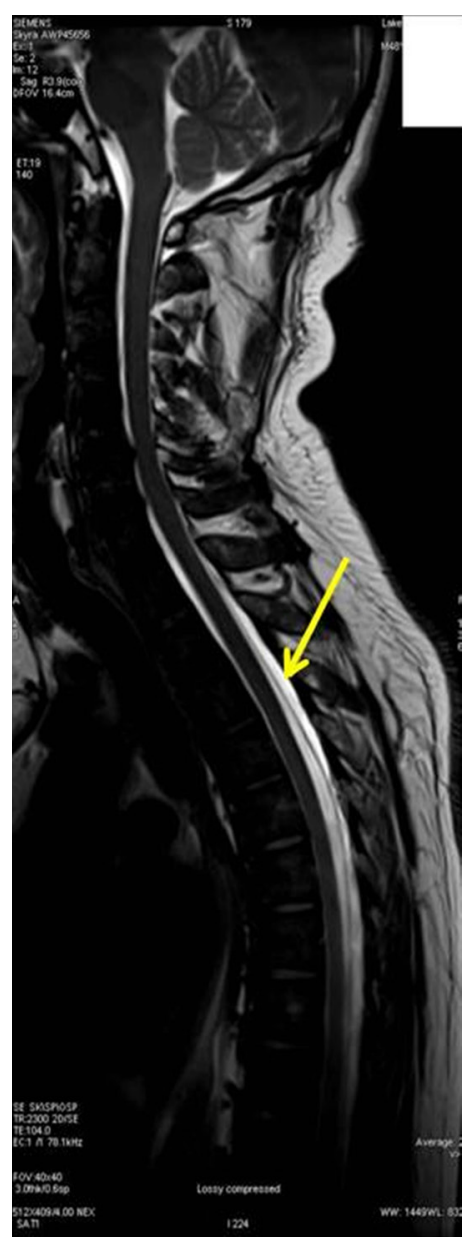

Figure 2: T2 sagittal sequence from the spine MRI showing elliptical high signal extra axial collection posterior to the spinal cordat T3 to T8 level (as marked by the arrow, suggestive of CSF leak)
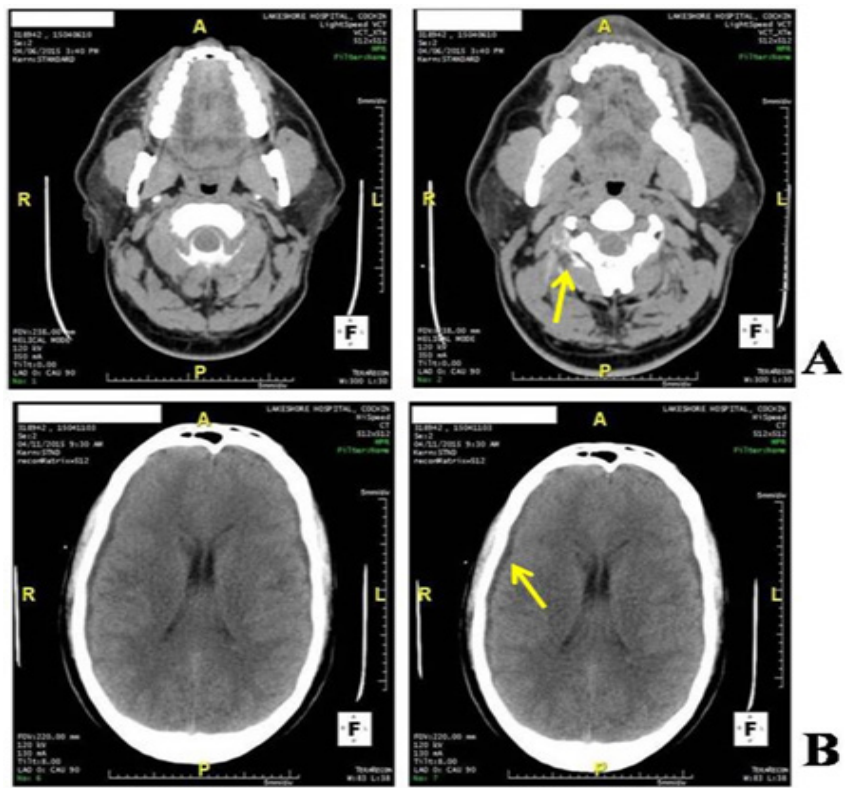

Figure 3: CT. (A) Myelography showing extradural contrast extravasation at C2C3 level (as marked by the arrow); (B) plain CT brain after epidural blood patch showing mild reduction in the extent of subdural effusions (as marked by the arrow)

mutation was also not detected.

The patient was advised complete bed rest with foot end elevation and to remain adequately hydrated.
Anticoagulation for CVT was precluded since he had bilateral subdural effusions and CVT was secondary to SIH. After $24 \mathrm{~h}$ of bed rest and adequate hydration, since the patient was very much symptomatic, a cervical autologous epidural blood patch with $10 \mathrm{~mL}$ of blood was performed under CT guidance and achieved the resolution of the symptoms within a week without worsening the CVT. Brain CT taken on day 5 following epidural blood patch showed mild reduction in the extent of subdural effusions [Figure 3B]. In addition, the patient showed no residual symptoms or recurrence at six-month follow-up.

\section{DISCUSSION}

Literature clearly defines clinical signs, typical MRI findings and treatment options of SIH. ${ }^{[3]}$ In an intact cranium, the total intracranial volume must be constant according to the Monroe-Kellie hypothesis. ${ }^{[4]}$ SIH usually occurs due to spontaneous CSF leaks in the inferior cervical and superior thoracic spine. Mechanical stress, meningeal diverticula and connective tissue diseases have been reported as the potential risk factors for the development of SIH.

The Monroe-Kellie hypothesis states that the decrease in intracranial blood volume is compensated by the dilatation of the cerebral veins. ${ }^{[4]}$ Furthermore, CSF loss reduces the CSF absorption into the cerebral venous sinuses leading to an increase in blood viscosity in the cerebral compartment.

In our patient, epidural blood patch was performed earlier within $24 \mathrm{~h}$ of conservative therapy since the patient was very much symptomatic and $\mathrm{SIH}$ was complicated with subdural effusions and CVT.

In 2015, Kapoor and Ahmed did a comprehensive electronic literature search to include studies that reported on performance of cervical EBPs in patients with CSF leak at the cervical level. ${ }^{[16]}$ Their review provides Class II level of evidence that cervical EBPs are safe and effective in reliving positional headache due to CSF leak. A total of 15 studies, reporting on 19 patients were included. All patients presented with a headache that increased in the standing position, and improved in the supine position. All patients were identified to have a CSF leak at the cervical level. Eight patients first underwent a lumbar EBP, without complete, long-term relief. All these patients, along with 11 patients who did not undergo a lumbar EPB prior to cervical EBP, reported complete, longterm pain relief. EBPs were mostly done in the prone position, using imaging guidance. An average of 5-8 $\mathrm{mL}$ of autologous blood was injected in the epidural space. No major neurological complications were 


\begin{tabular}{|c|c|c|c|c|c|c|c|}
\hline Authors & Year & Age & Gender & OP & Location of CSF leak & $\mathrm{AC}$ & EBP \\
\hline Flemming and Link ${ }^{[6]}$ & 2005 & 31 & $M$ & $?$ & Cervical/Thoracic & Yes & No \\
\hline Kataoka et al. ${ }^{[7]}$ & 2007 & 45 & M & 40 & Cervical/Thoracic & Yes & Yes \\
\hline Albayram et al. ${ }^{[8]}$ & 2007 & 45 & M & $?$ & Thoracic & Yes & Yes \\
\hline Wang et al. ${ }^{[9]}$ & 2007 & 33 & $\mathrm{~F}$ & 80 & Cervical & No & Yes \\
\hline Tan et al. ${ }^{[10]}$ & 2008 & 26 & $\mathrm{~F}$ & 50 & Thoracic & Yes & Yes \\
\hline Schievink and Maya ${ }^{[11]}$ & 2008 & 32 & M & 0 & Thoracic & Yes & Yes \\
\hline Schievink and Maya ${ }^{[11]}$ & 2008 & 43 & $M$ & 40 & Thoracic & Yes & Yes \\
\hline Dangra et al..$^{[13]}$ & 2011 & 35 & M & $?$ & Cervical & Yes & No \\
\hline M. C. Garcia-Carreira et al. ${ }^{[14]}$ & 2014 & 29 & $\mathrm{~F}$ & 30 & Thoracic & Yes & Yes \\
\hline M. C. Garcia-Carreira et al. ${ }^{[14]}$ & 2014 & 54 & M & 20 & Thoracic & Yes & Yes \\
\hline Present Case & 2015 & 48 & M & 50 & Cervical & No & Yes \\
\hline
\end{tabular}

CSF: cerebrospinal fluid; OP: opening pressure $\left(\mathrm{mm} \mathrm{H}_{2} \mathrm{O}\right)$; $\mathrm{AC}$ : anticoagulation; EBP: epidural blood patch; age (years); M: male; F: female.

reported in any patient.

In 2014, Garcia-Carreira et al. ${ }^{[14]}$ described two cases of spontaneous intracranial hypotension associated with cerebral venous thrombosis. In one case, extensive cerebral venous thrombosis involved the superior sagittal sinus and multiple cortical cerebral veins. In the other case, only a right frontoparietal cortical vein was involved. When spontaneous intracranial hypotension and cerebral venous thrombosis occur together, it raises difficult practical questions about the treatment of these two conditions. In most reported cases, spontaneous intracranial hypotension was treated conservatively and cerebral venous thrombosis was treated with anticoagulation. GarciaCarreira et al. ${ }^{[14]}$ supported aggressive treatment of the underlying cerebrospinal fluid leak.

Again in 2015, Wang E and Wang D reported a case of successful treatment of a patient with spontaneous intracranial hypotension correlated with MRI finding of cerebrospinal fluid (CSF) leak with extradural collection at the upper cervical spinal level. ${ }^{[17]}$ This patient received two lumbar epidural blood patches without lasting relief. Later on, the radiographic evidence of prominent CSF leak with extradural fluid collection was noted at C1-2 level. The patient was then treated with a cervical epidural blood patch, which provided headache pain relief lasting 6 months. A second cervical epidural blood patch was performed, and the patient was headache free since then.

Table 2 shows all the reported data of patients with cerebral venous thrombosis and spontaneous intracranial hypotension in whom the site of cerebrospinal fluid leak was demonstrated. All these patients who received EBP responded very well and was symptom free during the follow up.

There remain some controversies in treatment of SIH complicated with CVT. Primary conservative management of SIH accompanied by anticoagulation for CVT is usually advised. If the symptoms of $\mathrm{SIH}$ persist even after bed rest and adequate hydration, epidural blood patching could be considered. Anticoagulation for CVT can be withheld till the symptoms of SIH get controlled. The mortality of CVT is $5 \%$ but with $\mathrm{SIH}$, it can be increased. Therefore firstly SIH should be treated.

In 2013, Güler et al. ${ }^{[18]}$ reported a case of cerebral venous thrombosis accompanying with intracranial hypotension. They advocated anticoagulation for this patient only after SIH symptoms resolved. CVT is not reported in any $\mathrm{SIH}$ case after the resolution of symptoms. So, in our patient we tried to treat the primary cause, SIH and hence anticoagulation was precluded. We advocate primary treatment of the underlying spinal CSF leak, particularly when symptoms of SIH persist. In our patient, we did an autologous epidural blood patch at the site of CSF leak under CT guidance and the patient improved. In addition, the patient had no residual symptoms or recurrence at six-month follow-up. We think that our case can add additional information to the literature regarding the management of CVT in SIH.

\section{Financial support and sponsorship}

Nil.

\section{Conflicts of interest}

There are no conflicts of interest.

\section{REFERENCES}

1. Schievink WI. Spontaneous spinal cerebrospinal fluid leaks. Cephalalgia 2008;28:1345-56

2. Schievink WI. Spontaneous spinal cerebrospinal fluid leaks and intracranial hypotension. JAMA 2006;295:2286-96.

3. Mokri B, The Monro-Kellie hypothesis: applications in CSF volume depletion. Neurology 2001;56:1746-8.

4. Fabricius J, Klotz JM, Hofmann E, Behr R, Neumann-Haefelin T. Cerebral venous thrombosis and subdural hematoma: complications of spontaneous intracranial hypotension. Fortschr Neurol Psychiatr 2012; 80:599-601.

5. Flemming KD, Link MJ. Spontaneous CSF leak complicated by venous thrombosis and dural arteriovenous fistula. Cephalalgia 2005; 25:751-3.

6. Kataoka H, Tanizawa E, Ueno S. Spontaneous intracranial 
hypotension is associated with a risk of venous sinus thrombosis and subdural hematoma. Cerebrovasc Dis 2007;23:315-7.

7. Albayram S, Tasmali KM, Gunduz A. Can spontaneous intracranial hypotension cause venous sinus thrombosis? J Headache Pain 2007; 8:200-1.

8. Wang YF, Fuh JL, Lirng JF, Chang FC, Wang SJ. Spontaneous intracranial hypotension with isolated cortical vein thrombosis and subarachnoid hemorrhage. Cephalalgia 2007;27:1413-7.

9. Tan K, Venketasubramanian N, Hwang CY, Lim CC. My headache does not get better when I lie down: spontaneous intracranial hypotension complicated by venous thrombosis. Headache 2008;48:149-52.

10. Schievink WI, Maya MM. Cerebral venous thrombosis in spontaneous intracranial hypotension. Headache 2008; 48:15119.

11. Yoon KW, Cho MK, Kim YJ, Lee SK. Sinus thrombosis in a patient with intracranial hypotension: a suggested hypothesis of venous stasis. Interv Neuroradiol 2011;17:248-51.

12. Dangra VR, Sharma YB, Bharucha NE, Deopujari CE. An interesting case of headache. Ann Indian Acad Neurol 2011;14:1302.

13. Garcia-Carreira MC, Vergé DC, Branera J, Zauner M, Herrero JE, Tió E, Perpinyà GR. Cerebral venous thrombosis in two patients with spontaneous intracranial hypotension. Case Rep Neurol Med 2014;2014:528268.

14. Kim BW, Jung YJ, Kim MS, Choi BY. Chronic subdural hematoma after spontaneous intracranial hypotension: a case treated with epidural blood patch on c1-2. J Korean Neurosurg Soc 2011;50:274-6.

15. Kapoor SG, Ahmed S. Cervical epidural blood patch--A literature review. Pain Med. 2015; 16:1897-904.

16. Wang E, Wang D. Successful treatment of spontaneous intracranial hypotension due to prominent cervical cerebrospinal fluid leak with cervical epidural blood patch. Pain Med 2015;16:1013-8.

17. Güler S, Deniz Ç, Utku U, Kehaya S. A case of cerebral venous thrombosis accompanying with intracranial hypotension: headache that changing character. Agri 2013;25:141-4. 